\title{
DESCRIPTION OF AN ELECTRIC SIGNAL CLOCK.
}

\author{
By Aaron D. and Geo. W. Blodgett.
}

[A paper read at the stated meeting of the Franklin Institute, December 20 , 1882.]

The requirements of business at the terminus of a railway of any considerable magnitude necessitates the arrival and departure of a large number of trains.

The development of the country through which it passes, and the increased traffic which is the consequence thereof, call for constant addition to its facilities for the safe and convenient transportation of passengers.

The problem of dispatching fifty, sixty, or a hundred trains per day with promptness and regularity has become so important that only the most reliable men are considered competent for this work. But with the utmost care, mistakes are made and delays occur which are detrimental to the business of the road, and endanger the lives of its patrons.

The usual method of giving signals for the departure of railway trains is to put the signal bells in charge of the ticket agent, who, besides answering questions, selling tickets, and making change, gives signals for the trains to depart, as well as the usual preliminary signals.

It is not at all surprising that, as is always found to be the case, much irregularity exists in the time of the signals; that at the critical moment something else often engages the operator's attention, and the signal is delayed and sometimes forgotten; or in the effort to start trains promptly, it is given too early and the train departs before it should.

Careful observation shows that errors of this kind will happen with the most painstaking men, and even in cases where the operator's only business is to dispatch trains, the inaccuracy is greater than is commonly supposed.

Experience teaches that whenever machinery can be substituted for human labor, greater accuracy can be attained.

So far as we know, a machine has never yet been invented which would answer questions, sell tickets, or make change; but we are able to show a machine which will give correctly the warning and departure signals for any number of trains in their proper order. 
The essential features of this machine are:-

A cylinder which is provided with a separate hole for each minute in the twenty-four hours.

A shoe, or follower, is so contrived as to pass over every hole in the cylinder once a day. This is connected with suitable circuit-closing mechanism in such a way that a slight movement of the shoe away from the cylinder, will set in operation the signaling apparatus.

Small pins are screwed into the holes which correspond in location to the times when signals should be given.

The operation of the machine, which will be readily understood, is as follows :

A standard clock (which is to be found at every railway terminus), is caused to close an electric circuit in a well-known way once each minute.

The current passes through an electro-magnet connected by a pawl to a ratchet-wheel of sixty teeth, which it advances one tooth at each closure of the circuit.

This ratchet rotates the cylinder one step each minute, which, therefore, makes one revolution in an hour.

Most railroads require two signals for the departure of every train, a warning, or preliminary, signal which precedes the other by a certain interval - two, three, or five minutes-and a starting signal sounded at the exact time when the train should depart.

Whenever the follower comes in contact with the pin corresponding to a warning signal, the circuit-closing mechanism is released, and one or more blows are struck upon the bells, according to the signal required. After the lapse of the proper interval, the follower comes in contact with the second pin, and the signal is given for the train to start.

When the time of the next train approaches the operations are repeated, and so on through the time-table.

At twelve o'clock, midnight, the follower having completed its traverse of the holes in the cylinder, is automatically transferred to the first hole of the series and begins a new day.

The cylinder is provided with an additional series of fourteen hundred and forty holes, and with pins corresponding to a Sunday timetable.

A follower also traverses the holes in this part of the cylinder, but cannot set in motion the striking mechanism during a weekday. 
At midnight on Saturday the follower which could set in operation on a weekday the mechanism which strikes the bells, is disconnected, and the Sunday time-table rendered operative, striking the signals for trains on that day. At midnight, Sunday, things are restored to the first-described condition for six days more.

The instrument is, therefore, automatic in its operation, requiring only such changes as are necessary in the arrangement of pins, to correspond with changes in the time-table.

The circuit closing mechanism is driven by a spring which requires winding once a week.

A press-button and switch connected with the bells, and under control of the train-dispatcher, enables him to delay a regular signal, or to strike additional ones, should it be desired. Such interruption does not, however, in any way disarrange the apparatus, which, as soon as the switch is closed, resumes its normal operation.

One of these machines has been in use for nearly a year at the depot of the Boston and Albany Railroad, in Boston-the largest in the city -dispatching satisfactorily nearly sixty trains a day. Next in order comes the Boston and Providence Railroad, where over fifty trains a day are sent out in the same manner.

The New York and New England, and the Fitchburg Railroads follow with a less number of trains, which are also dispatched in this way.

The United States Government has recently ordered this machine for the Boston Post Office, where it signals the departure of the mails.

From the foregoing it will be seen that this instrument can be used for many other purposes besides those mentioned, such as, the distribution of standard time signals for manufacturing companies, for street railroads, and for use in school-buildings; in short, wherever it is desired to sound signals for any purpose, at regular or irregular intervals.

Any conceivable arrangement of signals is also permissible, the machines in operation at the Boston depots following each a different code.

Only one change is necessary to fulfil all these conditions, and that is simple, and easily made.

The operation of setting up or changing the time-table is so simple that it can be done by any person of average intelligence, with accuracy and in a few moments. 